\title{
In Vitro Selection of the Sunflower (Helianthus Annuus L.) Accessions under the Polyethylene Glycol Mediated Drought Stress Conditions
}

\author{
HumeraRazzaq, M. Hammad Nadeem Tahir, Hafeez Ahmad Sadaqat and Bushra Sadia
}

\begin{abstract}
Responses of the sunflower accessions to Polyethylene glycol (PEG-6000) mediated drought stress was examined in vitro culture under triplicate completely randomized deign. Three drought treatments i.e. $T_{1}=$ Zero (Control), $\mathrm{T}_{2}=-\mathbf{0 . 3 5} \mathrm{MPa}$ and $\mathrm{T}_{3}=-1.33 \mathrm{MPa}$ were developed. Seeds of the accession were grown on half strength MS media and three explants (leaf, stem, coleoptiles) were used for the callus culture. Stress was applied at the time of the media preparation for callus. Fifty petri plates of each accession were prepared and divided into two groups (Group I, Group II) containing 25 plated each. Petri plates of Group I were maintained for callus culture while of Group II were used for regeneration. Data were recorded from these groups on the traits i.e. relative fresh weight $(\mathrm{g})$, proline content $(\mu \mathrm{g})$, relative membrane leakage $(\mu \mathrm{g})$, total soluble sugar contents $(\mu \mathrm{g})$, coleoptiles length $(\mathrm{mm})$, root length $(\mathrm{mm})$, root count, fresh and dry root weight (g) and fresh and dry shoot weight (g). On the basis of the above parameters, the accessions A-23 and HBRS-1 were drought tolerant and 017577 as drought sensitive. In addition, the results of this study illustrate the potential of using in vitro culture for evaluation of drought tolerance at cellular level.
\end{abstract}

Keywords-Drought stress, In vitro, Polyethylene glycol, Sunflower

\section{INTRODUCTION}

Sunflower as an oilseed crop is becoming popular and it contributes globally about $87 \%$ in vegetable oil [1] so, it is considered as economically important crop in all over the world. But unfortunately unequal distribution of the rainfall and water shortage during its growing season has severe reduction in achene [2] and also in oil yield [3]. There are certain stages at which plants are badly affected by the drought such as germination, seedling and flowering [4]. Seed germination is the more critical and sensitive stage so, when this stage faces drought, seeds have to compromise for the establishment of the seedlings [5]. Germination percentage decreases and its time increases by increasing the drought levels [6], [7]. It had adverse effects at germination and seedling stage in sunflower [8] as well as in wheat [9] sugar beet [10] and sorghum. Therefore it is the need to grow drought tolerant cultivars which can express their full yield potential even under severe water scarcity.Selection of drought tolerance accessions from the available germplasm is the basic step to develop the drought tolerant varieties or hybrids.

Lecturer, University of Agriculture, Faisalabad, Pakistan
Plant breeders have used various selection methods to screen the drought tolerant accessions and also those traits which contribute in its tolerance. But uncontrolled conditions, heterogeneity in soil, huge amount of plant material, time and labour make the screening experiments more difficult. Hence laboratory experiments are more reliable and easy to conduct as compared to field trials. In laboratory, we have to create artificial drought stress. Polyethlylene glycol (PEG-6000) can be used as drought stimulator as it is considered as nonpenetrable, harmless and best way to create the drought stress condition.The objectives of this study were to estimate the genetic variability and also determine the effect of Polyethylene glycol as drought stimulator in sunflower accessions.

\section{MATERIAL AND MEthodS}

This study was carried out at the Somatic Cell Genetics Laboratory, University of Agriculture, Faisalabad.Sixteen sunflower accessions (A-75, A-79, A-48, A-23, G-61, G-33, HBRS-1, 017583, 017592, 017566, HA-341, HA-342, HA133, HA-124, CM-621 and 017577) were collected from the Department of Plant Breeding and Genetics, University of Agriculture, Faisalabad. Experiment was laid out under triplicate Complete Randomized design under factorial structured treatments.

IN VITRO CULTURE - Thirty achenes of each selected drought tolerant and sensitive accession were sterilized following method proposed by [11], [12].Achenes without pericarp were surface sterilized in $70 \%$ ethanol for 3 minutes, soaked for 20 minutes in $5 \%$ sodium hypochlorite solution with $0.01 \%(\mathrm{v} / \mathrm{v})$ tween-20 and rinsed five times in sterilized double distilled water.Half strength MS medium [13] was prepared.

Seed culture-Three sterilized seeds of each accession were cultured in three test tubes per replication. Each test tube was wrapped with clean film tape by using the proper rubber band and these cultured seeds were placed again in growth room for germination. Each test tube was observed daily for germination.

Callus culture - From two days old seedlings, three explants (leaf, stem and coleoptiles) of each accession per replication were used for callus culture. Total 50 petri plates of each accession were prepared using full strength MS medium [13] with prerequisite supplements for callus culture [11], [12] i.e. 1-Naphthly acetic acid $(5.4 \mu \mathrm{M})$, Benzyl aminopurine (4.4 $\mu \mathrm{M}), \mathrm{KNO}_{3}(50 \mu \mathrm{M})$, Myoinositol $(1 \mu \mathrm{M})$, Casein hydrolysate $(5 \mu \mathrm{M})$ and $5.6 \mathrm{pH}$ was maintained. 
Stress application - After 21 days of callus induction, fresh weight of callus from each petri plate per entry was weight by using the (Setra-SB4 105). After this, three treatments of PEG-6000 mediated drought stress i.e. 0 (control), -0.35 and $-1.33 \mathrm{MPa}$ were applied at the time of media preparation for sub culturing of callus. These 50 plates of each accession were divided into two groups, Group I and II, containing 25 plates each. Petri plates of Group I were maintained for callus culture while of Group II were used for the regeneration. After 14 days of treatment application, following parameters were recorded from Group I.

1.Relative fresh weight - Fresh weight of callus from each petri dish per treatment per replication was measured in grams using weighing balance (Setra-SB4 105) after stress induction. Relative fresh weight of callus was calculated by following formula:Relative fresh weight of callus $=\left(\mathrm{W}_{\mathrm{f}}-\mathrm{W}_{\mathrm{i}}\right) / \mathrm{W}_{\mathrm{i}}$

$\mathrm{W}_{\mathrm{f}}=$ Fresh weight of callus after stress application $\mathrm{W}_{\mathrm{i}}=$ Fresh weight of callus before stress application

2. Proline content- Freeproline content was measured spectrophotometrically according to the method of Bates[14].

3. Relative membrane leakage- Calli clumps were used for the determination of relative membrane leakage. Membrane damage was determined in terms of relative electrolytic leakage (REL) according to the method of Sullivan [15]. The REL was calculated as: $\mathrm{REL}=\left(\mathrm{EC}_{1} / \mathrm{EC}_{2}\right) \times 100$

4. Total soluble sugar contents - Total soluble sugar contents (TSS) were estimated following the anthrone method of Watanabe [16].

Regeneration from induced callus- Induced callus culture of Group II (25) were shifted to the regeneration media and kept in growth room at $25 \pm 1^{\circ} \mathrm{C}$ under $16 \mathrm{~h} \mathrm{light} / 8 \mathrm{~h}$ dark cycle with a light flux of $80 \mu \mathrm{mol} \mathrm{m} \mathrm{m}^{-2}$. Following traits were recorded from Group II after 21 days of treatment application in media of callus subculture.

Coleoptile and root length of each accession per treatment per replication was recorded in millimeter. Number of roots was counted of each accession from each treatment per replication.Fresh root and weight of each accession per treatment per replication was measured and then dried at $70^{\circ} \mathrm{C}$ in oven for one hour and weighed with weighing balance (Setra BL-410S) in grams.The recorded data was subjected to analysis of variance following by Steel et al. [17]

\section{Results ANd Discussion}

Polyethylene glycol induced drought stress significantly as interaction of accessions and PEG concentration was significant (Table 1). It suggests that PEG can be further used to create the drought stress as it caused the osmotic stress [18], [19]. In this research work PEG-6000 was used as drought stimulator as many scientists used it to induce the osmotic stress [6], [20] in growth room studies. Accessions and treatments had significant differences for all the studied parameters, which show that each accession behaves differently at the each treatment.

Polyethylene glycol (PEG-6000) induced water stress, significantly reduce the coleoptiles length. Coleoptile lengths were significantly decreasing by increasing the PEG concentration, trend was almost similar in drought tolerant and sensitive sunflower accessions. The accession A-23 had maximum coleoptiles length $(5.8 \mathrm{~mm})$ under the $\mathrm{T}_{1}, 017566$ had maximum $(0.6 \mathrm{~mm})$ under the $\mathrm{T}_{2}$ and HBRS-1 had maximum $(0.3 \mathrm{~mm})$ under $\mathrm{T}_{3}$. While the accession HA-342 had minimum coleoptile length $(0.133 \mathrm{~mm})$ under $\mathrm{T}_{1}$, while 017577 had $(0.133 \mathrm{~mm}, 0.1 \mathrm{~mm})$ under the $\mathrm{T}_{2}$ and $\mathrm{T}_{3}$ respectively. The decrease in coleoptiles length may be due to the osmotic regulation which enables them to maintain cell turgor pressure to help growth under the severe stress conditions. The variability in the decreasing trend of coleoptiles length indicates the genotypic variability under the PEG mediated drought stress conditions. Decrease in coleoptiles length was also reported in wheat [21], [22], [23], [24] in sorghum.

In the case or root length, sunflower accessions behave differently. As highest root length was observed at maximum PEG concentration in most of the accessions except A-79, A48, G-61, 017583 and 017579. The accession G-61 maintained its root length under the $\mathrm{T}_{1}$ i.e. $3 \mathrm{~mm}$ while $017583(1.17 \mathrm{~mm})$ under $\mathrm{T}_{2}$ and $\mathrm{G}-33(1.533 \mathrm{~mm})$ under $\mathrm{T}_{3}$. The accession CM621 had the lowest root length in T1 $(0.1 \mathrm{~mm}), 017577(0.13$ $\mathrm{mm})$ under $\mathrm{T}_{2}$ and HA-124 $(0.133 \mathrm{~mm})$ under $\mathrm{T}_{3}$. Response of root length under drought stress conditions varies, as sometime in limits its growth due the unavailability of water and sometime in increases its growth to enhance the water spendors[25]. Root growth directly links to the drought tolerance as it is closely related to the uptake of the water. Tolerant accessions must have the highest and robust root growth in comparison to sensitive accessions. Severe reduction in root length is observed in cereals [26], [27].

Trend in the number of roots were different in all the accessions, overall accessions showed the maximum number of roots at the highest PEG concentration. Trend was genotype dependent. Overall among the studied accessions, 017583, HA-341 and A-48 maintained the root count under the $T_{1}, T_{2}$ and $\mathrm{T}_{3}$ respectively i.e. $6,5,6$. Minimum root counts were observed in the accessions HA-133 (2) under $\mathrm{T}_{1}, 017579$ (2 and 1) under $T_{2}$ and $T_{3}$ respectively. The ability to maintain the number of roots in sunflower accession indicates the drought tolerance. Drought stress conditions favours the lateral roots particularly in seedlings [28]. In this experiment increase in number of roots may be due to enhance the water uptake under PEG mediated water deficit conditions. Roots numbers were also increased in sugarcane on culture media supplemented with the PEG concentrations [29].

Root dry weights were significantly decreasing by increasing the PEG concentrations. As the accession HBRS-1 had maximum root dry weight (40.98 g) under $\mathrm{T}_{1}, \mathrm{G}-61(0.73$ g) under $T_{2}$ and $017583(0.73 \mathrm{~g})$ under $T_{3}$. While the accessionHA-133 showed the minimum root dry weight $(2 \mathrm{~g})$ under $\mathrm{T}_{1}$ and $017579 \mathrm{had}(2.33 \mathrm{~g}$ and $1.6 \mathrm{~g})$ under $\mathrm{T}_{2}$ and $\mathrm{T}_{3} . \mathrm{In}$ case of shoot dry weight trend was almost similar to the root dry weight so, by increasing the PEG concentrations, shoot dry weight was decreasing. The accessions A-48 maintained the shoot dry weight $(0.5667 \mathrm{~g})$ under $\mathrm{T}_{1}, 017579(0.467 \mathrm{~g})$ under $\mathrm{T}_{2}$ and A-79 $(0.1)$ under $\mathrm{T}_{3}$. While minimum shoot dry weight value was observed in the accession HA-342 (0.103 g) under $\mathrm{T}_{1}, \mathrm{HA}-124(0.09 \mathrm{~g})$ under $\mathrm{T}_{2}$ and CM-621 $(0.07 \mathrm{~g})$ under $T_{3}$. Reduction in shoot length is mostly linked to the drought tolerance in cereals [30].Shoot dry weight is reduced mainly due to the increase portioning of solutes in roots as a 
mean of osmotic regulation [31], [32]. Decrease in shoot weight is common behavior of the plants under moisture deficit condition [33], [34]. When plants face stress condition, they start to accumulate some kinds of organic and inorganic solutes in their cytosol to maintain the osmotic pressure and maintain the both turgor and driving gradient for water uptake. Resources accumulate in the roots rather than the shoot under mild stress condition.

Relative fresh weight of callus was decreasing by increasing the PEG concentrations. The accessions A-23 had the maximum relative fresh weight of callus $(6.33 \mathrm{~g})$ under $\mathrm{T}_{1}, \mathrm{~A}$ 48 under $\mathrm{T}_{2}(8.66 \mathrm{~g})$ and $\mathrm{A}-79$ under $\mathrm{T}_{3}(7 \mathrm{~g})$. The lowest value of relative fresh weight of callus was observed in the accession CM-621 (-6.21g, - $0.33 \mathrm{~g}, 0 \mathrm{~g})$ under $\mathrm{T}_{1}, \mathrm{~T}_{2}$ and $\mathrm{T}_{3}$ respectively. The reduction in callus growth may be due to the fewer uptakes of nutrients under limited water stress conditions [35] and consequently the injury of cell membrane which is also measured in thus study [36], [37].

Accumulation of osmoticum is an indication of oxidative damage which provides protection to cytosol from dehydration and maintains turgor pressure. In the presence study proline contents were increasing by increasing the PEG mediated drought stress. The accession HA-133 had the maximum proline contents $(0.423 \mu \mathrm{g}, 0.53 \mu \mathrm{g})$ under the $\mathrm{T}_{1}$ and $\mathrm{T}_{3}$ respectively. While the accession 017577 had maximum proline contents i.e. 0.567 under $T_{2}$. The accession G-33 had the minimum proline content $(0.10 \mu \mathrm{g})$ under $\mathrm{T}_{1}, \mathrm{HA}-341$ $(0.1021 \mu \mathrm{g})$ under $\mathrm{T}_{2}$ and HA-124 $(0.1468 \mu \mathrm{g})$ under $\mathrm{T}_{3}$. Proline contents act as the osmotica in the presence of water scarcity and play a major role in the maintenance of osmotic balance [38] which is higher in drought tolerant species rather than the sensitive. Similarly accumulation of proline is also observed in many other species under stress conditioned.

Trend mean values of total soluble sugar contents were almost similar to the proline contents. The accession A-75 maintained the total soluble sugar contents $(0.735 \mu \mathrm{g}, 0.739$ $\mu \mathrm{g})$ under $\mathrm{T}_{1}$ and $\mathrm{T}_{2}$ while G-61 $(0.53 \mu \mathrm{g})$ under $\mathrm{T}_{3}$. The minimum accumulation of the proline contents was observed in accession $017577(0.365 \mu \mathrm{g})$ under $\mathrm{T}_{1}$ and HA-342 $(0.265$ $\mu \mathrm{g}, 0.1239 \mu \mathrm{g}$ ) under $\mathrm{T}_{2}$ and $\mathrm{T}_{3}$ respectively. Accumulation of the total soluble sugar contents also imparts the osmotic adjustment of cells under stress conditions. Sugar contents also observed in P.euphratica[16], [34].

Relative membrane leakage was higher by inducing the PEG mediated drought stress. The accession HA-123 had the lowest relative membrane leakage percentage $(0.2133 \%)$ at the $\mathrm{T}_{1}$, HBRS-1 $(0.49 \%)$ at $\mathrm{T}_{2}$ and G-33 $(0.265 \%)$ at $\mathrm{T}_{3}$ Highest percentage value is observed in $017577(0.64 \%, 0.512 \%)$ at $\mathrm{T}_{1}$ and $\mathrm{T}_{3}$ respectively, HA-124 $(0.703 \%)$ at $\mathrm{T}_{2}$. A progressive increase in relative membrane leakage was observed by increasing the PEG mediated drought stress [37] as well as in callus culture of sugarcane [35] and tobacco. Membrane leakage suggests the leakage of electrolyte outside the cell and reduction in growth as well as water content of the cell.On the base of the above studied parameters, the accessions A-23 and HBRS-1 are drought tolerant followed by A-75, A-48 and 017583. The accession 017577 is drought sensitive followed by CM-621 and HA- 124 .

Further the results of this study illustrate the potential of using cell and tissue culture for evaluation of drought tolerance at cellular level, since responses are relatively fast, the generation time are short, and the environment is controlled.

\section{REFERENCES}

[1] Murphy, D.J. 2010. Improvement of industrial oil crops, In: singh, B. (ed) Industrial crops and used .CABI.Int. Cambridge pp. 183-206. http://dx.doi.org/10.1079/9781845936167.0183

[2] Tahir, M.H.N., I. Muhammad and M.K.Hussain. 2002. Evaluation of sunflower (Helianthus annuиs L.) inbred accessions for drought tolerance. Int. J. Agric. Biol. 3: 398-400.

[3] Razi, H. and M.T. Assad. 1999. Comparison of selection criteria in normal and limited irrigation sunflower. Euphytica 105: 83-90. http://dx.doi.org/10.1023/A:1003472212917

[4] Ashraf, M. and S. Mehmood. 1990. Response of four brassica species to drought stress. Environ. Expt. Bot. 30: 93-100. http://dx.doi.org/10.1016/0098-8472(90)90028-3

[5] Albuquerque, F.M.C. de and N.M drCarvallho. 2003. Effect of type of environmental stress on the emergence of sunflower (Helinathusannuи L.), soybean (Glycine max L. Merril) and maize (Zea mays L.) seeds with different levels of vigor. Seed Sci. Technol. 31: 465-467. http://dx.doi.org/10.15258/sst.2003.31.2.23

[6] Smok, M.A., M. Chojnowski, F. Corbineau and D. Come. 1993. Effects of osmotic treatments on sunflower seed germination in relation with temperature and oxygen. In: Proc. $4^{\text {th }}$ Intl. workshop on seed: Basic and Applied aspects of seed biology (Eds) D. Come and F. Corbineau Angers, France, pp. 1033-1038.

[7] Sajjan, A.S., V.P. Badanur and G.M. Sajjanar.1999. Effect of external water potential on seed germination, seedling growth and vigour index in some genotypes of sunflower In: Proc. Symp. Recent advances in management of Arid ecosyststems (Eds.): SA Faroda, N.L. Joshi, S. Kathju and A. Kar pp: 215-218.

[8] Mohammad, M. El., M. Benbella and A. Talouizete. 2002. Effect of sodium chloride on sunflower (Helinanthusannuиs L.) seed germination. Helia 37: 51-58.

http://dx.doi.org/10.2298/HEL0237051M

[9] Dhanda, S.S., G.S. Sethi and R.K. Behl. 2004. Indices of drought tolerance in wheat genotypes at early stage of plant growth and soluble sugar content of Sorghum bicolor L. Moench seeds. Bulg. J. Plant Physiol. 28: 12-25.

[10] Sadeghian S.V. and N. Yavari. 2004. Effect of water deficit stress on germination and early seedling growth in sugarbeet. J. Agron. Crop Sci. 190: 138-144. http://dx.doi.org/10.1111/j.1439-037X.2004.00087.x

[11] Abdoli, M., A. Moieni and H. Dehghani. 2007. Effects of cultivar and agar concentration in vitro shoot organogenesis and hyperhydricity in sunflower (Helinathusannuus L.). Pakistan J. Bot. 142: 21-30.

[12] Tsago, Y., M. Andargie and A. Takele. 2014. In vitro selection of sorghum (Sorghum bicolor L. Moench) for Polyethylene glycol induced drought stress. Plant Sci. Today: 62-68.

[13] Murashige, T. and A. Skoog. 1962. A revised medium for rapid growth and bioassay with tobacco culture. Physiol. Plants 15: 473-497. http://dx.doi.org/10.1111/j.1399-3054.1962.tb08052.x

[14] Bates, L.S., R.P. Waldern and I.D. Teare. 1973. Rapid determination of free proline for water stress studies. Plant Soil 39: 205-207. http://dx.doi.org/10.1007/BF00018060

[15] Sullivan, C.V. 1972. Mechanism of heat and drought resistance in grain sorghum and methods of measurement. In: NGP, House LR(eds) Sorghum in the seveneties. Oxford and IBH, New Delhi pp. 247-264.

[16] Watanabe, S., K. Kojima, Y. Ide and S. Sasaki. 2000. Effects of saline and osmotic stress on proline and suage accumulation in populous euphyticain vitro: Plant Cell Tissue Organ Cult. 63: 199-206.

http://dx.doi.org/10.1023/A:1010619503680

[17] Ashraf, M.Y., m.H. Naqvi and A.H. Khan. 1990. Evaluation of four screening technique of drought tolerance in wheat (Triticumaestivum L.) ActaAgron. Hung. 44: 213-220.

[18] Turhan, H. 1997. Salinity studies in potato (Solanumtubersom L.) PhD Thesis, The University of Reasing, UK pp. 247.

[19] Hu, F.D. and R.J. Jones. 2004. Efefets of plant extracts of Bothriochloupertosaand Nrochloamosambicensis on seed germination and seedling growth of Stylosantheshamata cv. Verano and stylosanthesscabra cv. Seca. Aust. J. Agric. Res. 48: 1257-1264. 
http://dx.doi.org/10.1071/A97036

[20] Raziuddin, Z. J. Swati, B. Bakht, M. Ullah, M. Shafi, M. Akmal and G. Hassan. 2010. In situ assessment of morpho-physiological response of wheat (Triticumaestivum L.) genotypes to drought Pak. J. Bot. 42(5): 3183-3195.

[21] Takele, A. 2000. Seedling emergence and of growth of sorghum genotypes under variable oil moisture deficit.ActaAgronomicaHungarica 48(!): 95-102.

[22] Ambika, R. A. Reiendroin, R. Muthiah, A. Manickam, P. Shanmugasundavam, A.J. Joel. 2011. Indices of drought tolerance in sorghum (Sorghum bicolor L.) genotypes at early stages of plant growth. Res. J. Agric. And Biol. Sci. 42-46.

[23] Khodarahumper, Z. 2011. Efefcts of drought stress induces by Polyethylene glycol on germination indices in corn (Zea mays L.) hybrids. Africans J. Biotechnol. 10(79): 18222-18227,

[24] Parasad, P.V.V., S.A, Staggenberg and Z. Ristic. 2008. Impact of drought and heat stress on physiological, growth and yield processes: In L.H. Ahuja and S.A. Saseendran (Eds.) Modeling water stress effects on plant growth process. Advances in Agric. Systems Modeling.

[25] Ali, G., A.C. Rather, S.A. Dar, S.A.Wani and M.N. Khan. 2007. Gene action for grain yield and its attributes in maize (Zea mays L.) Int. J. Agric. Sci.: 278-281.

[26] Abd Allah, A.A., A.Shimaa, B. Badawy, A. Zayed and A.A. El-Gohary. 2010. The role of root system traits in the drought tolerance of rice (Oryza sativa L.): World Academy of Sci. EnginerringandTechnol. 4184: 1156-1160.

[27] Begum, M.K., M.O. Islam, M.A.S. Miah, M.A. Hossain and N. Islam. 2011. Production of somaclonein vitro for drought stress tolerant plantlet selection in sugarcane (Saccharumofficinarum L.) Agricukturists 9: 1828.

[28] Bibi, A., H.A. Sadaqat, M.H.N. Tahir and M.H. Akram. 2012. Screening of sorghum (Sorghum bicolor var. Moench) for drought tolerance at seelding stage in polyethylene glycol. The J. Animal and Plant Sci. 22)3): 671-678.

[29] Raw, S.V., S.P. Palaniappan and R. PAnchanathan. 2008. Growth and dry matter partitioning of sorghum under moisture stress condition. J. of Agronomy and Crop Science 166: 273-277.

[30] Addisie, V. 2010. Evaluation of sorghum (Sorghum bicolor L.) genotypes for post-flowering drought resistance (stay green trait) MSc. Thesis Addis Ababa University ,Ethopia.

[31] Sharp, R.E. and W.J. Davies. 1979. Solute regulation and growth by roots and shoots of water-stressed maize plants: Planta 147: 43-49. http://dx.doi.org/10.1007/BF00384589

[32] Creelman, R.A., H.S. Mason, R.J.BEnsen, S.S. Boyer and J.E. Mullet. 1990. Water deficit and absicic acid cause differential inhibition of shoot versus root growth in soybean seedlings. Plant Physiol. 92: 205-214. http://dx.doi.org/10.1104/pp.92.1.205

[33] Patade, V.Y., P. Suprasanna and V.A. Bapat. 2008. Effects of salt stress in relation to osmotic adjustment on sugarcane (Saccharumofficinarum L.) callus cultures. Plant Growth Regulators 55: 169-173. http://dx.doi.org/10.1007/s10725-008-9270-y

[34] Tabaei-Aghdaei, S.R., P. Harrison and R.S. Pearce. 2000. Expression of dehydration-stress-related genes in the crowns of wheat grass species (Lophophyrumelongatum (host) A. love and Agropyrondesertorum (fisch ex link)Schult) having contrasting acclimination to salt, sold and drought. Plant Cell and Environment 23: 561-571. http://dx.doi.org/10.1046/j.1365-3040.2000.00572.x

[35] Farooq, S. and F. Azam. 2006. The use of cell membrane stability (CMS) technique to screen for salt tolerant wheat varieties. J. Plant Physiol. 163: 629-637. http://dx.doi.org/10.1016/j.jplph.2005.06.006

[36] Zhang, F., Y.L. Yang, W.L. He, X. Zhao and X.L. Zhang. 2004. Effects of salinity on growth and compatible solutes of callus induced from Populuseuphytica. In vitro Cell Dev. Biol. Plant 40: 491-494. http://dx.doi.org/10.1079/IVP2004546

TABLE :I Mean square values from analysis of variance for studied traits in sunflower accessions under PEG-6000 stimulated drought stress conditions

\begin{tabular}{|l|l|l|l|l|l|l|l|l|l|l|}
\hline SOV & DOF & $\begin{array}{l}\text { CL } \\
(\mathrm{mm})\end{array}$ & $\begin{array}{l}\text { RL } \\
(\mathrm{mm})\end{array}$ & RC & RDW $(\mathrm{g})$ & SDW $(\mathrm{g})$ & RFWC $(\mathrm{g})$ & PC $(\mu \mathrm{g})$ & TSS $(\mu \mathrm{g})$ & RML $(\mu \mathrm{g})$ \\
\hline Accessions (A) & 15 & $2.01^{*}$ & $0.88^{*}$ & $4^{*}$ & $0.15^{*}$ & $0.19^{*}$ & $23.3^{*}$ & $0.06^{*}$ & $0.07^{*}$ & $0.04^{*}$ \\
\hline Treatments (T) & 2 & $9.94^{*}$ & $8.49^{*}$ & $2^{*}$ & $1.39^{*}$ & $0.17^{*}$ & $43.9^{*}$ & $0.33^{*}$ & $0.08^{*}$ & $4.17^{*}$ \\
\hline A $\times$ T & 30 & $1.72^{*}$ & $0.365^{*}$ & $3^{*}$ & $0.07^{*}$ & $0.04^{*}$ & $17.96^{*}$ & $0.06^{*}$ & $0.05^{*}$ & $0.06^{*}$ \\
\hline Error & 94 & $1.64^{*}$ & $0.084^{*}$ & $3^{*}$ & $0.04^{*}$ & $0.02^{*}$ & $4.82^{*}$ & $0.04^{*}$ & $0.04^{*}$ & $0.34^{*}$ \\
\hline
\end{tabular}

